\title{
Primary amnesia of insidious onset with subsequent stabilisation
}

\author{
F Lucchelli, E De Renzi, D Perani, F Fazio
}

\begin{abstract}
A patient had a slowly developing amnesic syndrome that remained substantially unchanged during the two and a half years of observation. Intellectual skills were excellent and there was no language, perception, praxis, or calculation deficit. The memory impairment involved verbal and visual learning, sparing spatial learning and, to a large extent, retrograde memory. Magnetic resonance imaging was normal, but PET showed a hypometabolism of the left temporal mesial region and thalamus. This case extends the spectrum of monosymptomatic cognitive disorders, previously reported in the area of language, praxis, and visual recognition, to amnesia.
\end{abstract}

(F Neurol Neurosurg Psychiatry 1994;57:1366-1370)

In 1982 a report by Mesulam $^{1}$ rekindled interest on a syndrome characterised by slowly progressive aphasia in the absence of other cognitive deficits. This syndrome had, until then, been largely neglected by neurologists. Its clinical status has now been confirmed by several case reports, although the question remains as to whether slowly progressive aphasia is an autonomous entity, consequent to a degenerative process confined to the left hemisphere speech region, or the early manifestation of a more generalised disease, eventually resulting in global mental deterioration. Clinical and pathological findings seem to indicate that the aetiology and evolution. of slowly progressive aphasia is heterogeneous, with a few cases showing aphasia as the only symptom for long periods and possibly for the rest of their lives and others evolving towards more common forms of degenerative dementias, such as Alzheimer's and Pick's disease. ${ }^{2}$

With the upsurge of interest in slowly progressive aphasia, neurologists have begun to turn their attention to the possibility that there may be other progressive cognitive disorders confined to a single ability. Cases of isolated apraxia ${ }^{34}$ or agnosia ${ }^{35}$ have been reported, although they are fewer than those of aphasia and lack pathological documentation.

In this paper we report a patient with an amnesia not accompanied by other cognitive disorders, that progressed over a few years, reached a plateau, and then remained unchanged during the two and half years of follow up. A PET study of cerebral metabo- lism showed a selective impairment of memory related structures.

\section{Case report}

The patient is a 69 year old right handed woman with a degree in pharmacology who was referred to our outpatient clinic in November 1990 for memory complaints. A grandfather, an aunt, and two first cousins, all belonging to her father's side of the family, were reported to have had cognitive disorders late in life; unfortunately these could not be better specified. One of her father's brothers was affected with Down's syndrome. The patient married at the age of 27 , had four children (one of them is schizophrenic), and worked as a junior high school teacher of mathematics and science until 1984, when she retired. Her medical history is unremarkable, apart from hypertension that has been treated successfully for 10 years. She was uncertain when her memory disorder had started, but tended to date it back to the last years of teaching, when she had had increasing difficulty in preparing her lessons. They were not initially perceived by her husband, who became aware of them from 1987, when he noticed that she tended to repeat the same questions at short intervals, often missed appointments, and had to rely on shopping lists. She never lost her way in familiar surroundings. Although her relatives were uncertain about the rate of progression. of the disease, they were adamant in stating that it had developed slowly and that its onset could not be dated with precision.

We saw the patient for three sessions between November 1990 and March 1991 and again in follow up examinations carried out in October 1992 and August 1993. Throughout this period the neurological examination remained unremarkable. She was a gentle, well groomed, and cooperative person, aware of her memory problems and concerned about her future. She was oriented to time and space, paid close attention to questions, and quickly understood them. She spoke fluently and properly without any sign of anomia.

The memory deficit was easily brought out in conversation. She was unable to report what she had eaten at lunch, did not remember from one session to the next the tasks she had been given, sometimes asked the examiner to repeat the instructions during the execution of a task, as she had forgotten what to do, and had a vague and patchy recollection of famous 
Table 1 Language, calculation, visual perception, and praxis tests

\begin{tabular}{ll}
\hline Token test & $32 / 36$ \\
Boston naming test & $69 / 85$ \\
Verbal fluency (P, F, L) & 47 \\
Calculation & $25 / 27$ \\
Unknown face identification & $23 / 27$ \\
Figure ground discrimination & $33 / 33$ \\
Limb praxis & $70 / 72$ \\
Oral praxis & $24 / 24$ \\
Constructional praxis & $20 / 20$ \\
\hline
\end{tabular}

public events that had occurred in the past months.

\section{FIRST NEUROPSYCHOLOGICAL EXAMINATION \\ (NOVEMBER 1990-MARCH 1991)}

The patient had an IQ of 132 on the WAIS (revised) with a VIQ of 133 and a PIQ of 127. She scored 44/48 on Raven PM38, found all of the six criteria of classification on the Wisconsin test with 98 cards and produced 47 names in three minutes on verbal fluency on phonetic cues $(\mathrm{P}, \mathrm{F}, \mathrm{L})$.

Language, calculation, visual perception, and oral and limb praxis were assessed with appropriate tests, on all of which she scored well in the normal range (table 1). The only area in which she performed poorly was learning.

Table 2 reports the scores, corrected for age and educational level, achieved on learning tests, for most of which a cut off point discriminating a normal from a pathological performance is available, based on the score distribution of 100 normal controls. ${ }^{6}$ Partial regression coefficients of the scores on age and education provided the correction for these variables. The verbal tests were story recall (immediate and after a 10 minute filled delay), paired associate learning (five easy and five difficult associations) over three trials, and 10 word learning (carried out to the criterion of two successful consecutive recalls, the score being the sum of words recalled over trials divided by the number of trials to criterion).

Table 2 Learning tests

\begin{tabular}{lcccc}
\hline & 1991 & 1992 & 1993 & Cut off point \\
\hline Digit span & 7 & 6 & 7 & \\
Story recall & $1 \cdot 15$ & 5 & $4 \cdot 40$ & $15 \cdot 76$ \\
Paired associates & $4 \cdot 38$ & $3 \cdot 5$ & $4 \cdot 45$ & $8 \cdot 73$ \\
Learning 10 words & $7 \cdot 93$ & $5 \cdot 55$ & $6 \cdot 86$ & $6 \cdot 58$ \\
Recurring face recognition & $29 \cdot 56$ & $30 \cdot 66$ & $24 \cdot 60$ & $33 \cdot 37$ \\
Rey figure & $6 \cdot 84$ & - & 0 & $12 \cdot 39$ \\
Cube span & 7 & 6 & 6 & - \\
Cube supraspan & 4 & 10 & - & - \\
$\quad$ (trial to criterion) & 11 & - & - & - \\
\hline
\end{tabular}

Table 3 Retrograde memory tests

\begin{tabular}{lllll}
\hline & 1991 & 1992 & 1993 & Cut off point \\
\hline Questionnaire & 40.53 & - & 35.17 & 41.53 \\
Famous names & -1.22 & - & -1.32 & -2.05 \\
Familiar faces & 1.00 & - & 2.15 & 2.99 \\
Famous faces & - & & & \\
\hline
\end{tabular}

The scores of both face tests refer to standardised error scores, corrected for age and education. Thus the lower the score, the better the performance.
The two visual memory tests were Rey's figure reproduction from memory after a 10 minute filled delay, and a test of recurring unknown face recognition, in which eight target faces had to be identified from among 12 foil faces in three successive presentations. Its score is the sum of hits minus the sum of false positives. The patient's scores, corrected for age and education, fell below the cut off point on two out of three verbal memory tests ${ }^{6}$ and on both visual memory tests. ${ }^{7}$ In contrast, her performance on two spatial learning testssupraspan learning on Corsi's block tapping test and maze learning on a stepping stone visual maze test - was within the normal range (controls' means 13 trials to criterion in both cases).

Retrograde memory was investigated with four tests (table 3). The first two were verbal and comprised a famous event questionnaire and a famous name recognition test. The questionnaire, given in a recognition format, consisted of eight questions for the biennium 1965 to 1985 , with four choices for questions (the target and three foils) ${ }^{8}$ For name recognition 30 famous names (Christopher Columbus, Wolfgang Mozart, etc) intermingled with 30 unknown names were presented one at a time. The two visual tests were a face familiarity test and a famous face recognition test. ${ }^{9}$ The first required the patient to select the one face that was familiar from an array of four photographs, the second to point to the face of a famous person named by the examiner, when it was presented with three distractors belonging to the same sex and semantic area (for example, four Italian presidents). Cut off points, corrected for age and education, have been determined for all of these tests, ${ }^{89}$ except that dealing with famous and unknown names.

Table 3 shows that she scored below the normal range on the questionnaire, but not on the other tests.

Autobiographical memory was investigated with a structured interview, covering events of her past life from youth to recent years. Information provided by her husband and daughter was used in the preparation. Episodes occurring before the onset of disease were recollected fairly accurately and the forgotten details were recovered when a cue was provided. Recall was much patchier and less accurate for the events of the past two or three years (for instance, she had forgotten the holidays spent in Greece during the previous summer).

FOLLOW UP EXAMINATIONS (OCTOBER 1992 AND AUGUST 1993)

The patient was re-examined in October 1992 and August 1993. Both she and her husband were of the opinion that the memory deficit was unchanged and that there was no impairment in other cognitive areas. This was confirmed by formal testing. Raven PM38 (44/48 and 40/48) and language scores were still high and no definite evidence of further deterioration was found in her performance on memory tests (tables 2 and 3 ). 
Figure 1 MRI section showing the integrity of the hippocampus.

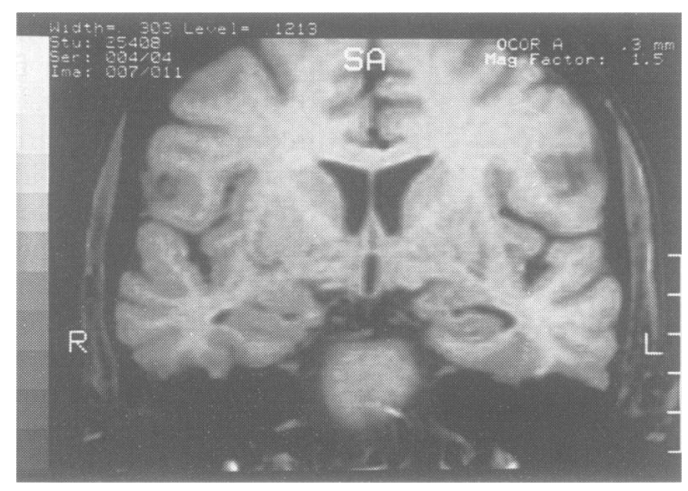

CT, MRI, AND PET

Neither CT nor MRI showed ventricular or subarachnoid changes indicative of atrophy, or evidence of brain damage. Figure 1 shows an MRI coronal section to demonstrate the integrity of the hippocampal region.

An $\left[{ }^{18} \mathrm{~F}\right]$ FDG PET study was performed in the resting state with open eyes and unplugged ears, using a Siemens/CPS, 931-04/12 positron emission tomograph. Image analysis was performed with software

Table 4 Mean (SD) of LCMRG1c ( $\mathrm{mg} / 100 \mathrm{~g} / \mathrm{min})$

\begin{tabular}{|c|c|c|c|c|}
\hline \multirow[b]{2}{*}{ Regions } & \multicolumn{2}{|c|}{ Left hemisphere } & \multicolumn{2}{|c|}{ Right hemisphere } \\
\hline & Patients & Controls & Patients & Controls \\
\hline $\begin{array}{l}\text { Cingulus } \\
\text { Frontal: }\end{array}$ & $5 \cdot 06$ & $6 \cdot 76(0.58)$ & $4 \cdot 98$ & $5 \cdot 84(0 \cdot 82)$ \\
\hline $\begin{array}{l}\text { Basal } \\
\text { Lateral } \\
\text { Rolandic } \\
\text { Parietal }\end{array}$ & $\begin{array}{l}6 \cdot 03 \\
6 \cdot 73 \\
7 \cdot 15 \\
6 \cdot 69\end{array}$ & $\begin{array}{l}6.25(0.75) \\
6.81(0.76) \\
6.62(0.64) \\
6.52(0.56)\end{array}$ & $\begin{array}{l}6 \cdot 48 \\
6 \cdot 63 \\
7 \cdot 19 \\
6 \cdot 74\end{array}$ & $\begin{array}{l}6 \cdot 16(0.66) \\
6 \cdot 73(0.62) \\
6 \cdot 59(0.52) \\
6 \cdot 57(0.56)\end{array}$ \\
\hline $\begin{array}{l}\text { Temporal: } \\
\text { Polar } \\
\text { Superior } \\
\text { Middle/inferior } \\
\text { Mesial (hippocampus) }\end{array}$ & $\begin{array}{l}5 \cdot 06 \\
6 \cdot 28 \\
6 \cdot 11 \\
3 \cdot 71^{\star}\end{array}$ & $\begin{array}{l}4 \cdot 70(0.48) \\
6 \cdot 17(0.52) \\
5 \cdot 94(0.62) \\
4.54(0.39)\end{array}$ & $\begin{array}{l}5 \cdot 25 \\
6 \cdot 59 \\
6 \cdot 37 \\
4 \cdot 67\end{array}$ & $\begin{array}{l}4 \cdot 42(0 \cdot 45) \\
6 \cdot 16(0 \cdot 52) \\
5 \cdot 83(0 \cdot 58) \\
4 \cdot 58(0 \cdot 41)\end{array}$ \\
\hline $\begin{array}{l}\text { Occipital: } \\
\text { Lateral } \\
\text { Calcarine } \\
\text { Caudate } \\
\text { Putamen }\end{array}$ & $\begin{array}{l}7 \cdot 11 \\
8 \cdot 35 \\
6 \cdot 67 \\
8 \cdot 11\end{array}$ & $\begin{array}{l}6 \cdot 41(0 \cdot 89) \\
7 \cdot 61(1 \cdot 04) \\
6 \cdot 76(0 \cdot 81) \\
7 \cdot 27(0 \cdot 78)\end{array}$ & $\begin{array}{l}7 \cdot 10 \\
8 \cdot 30 \\
6 \cdot 85 \\
7 \cdot 82\end{array}$ & $\begin{array}{l}6 \cdot 43(0 \cdot 68) \\
7 \cdot 74(0 \cdot 98) \\
6 \cdot 63(0 \cdot 73) \\
7 \cdot 21(0 \cdot 60)\end{array}$ \\
\hline $\begin{array}{l}\text { Thalamus (whole) } \\
\text { Anterior sector } \\
\text { Middle sector } \\
\text { Posterior sector } \\
\text { Cerebellum }\end{array}$ & $\begin{array}{l}5 \cdot 02^{\star} \\
4 \cdot 59^{\star} \\
4 \cdot 86^{\star} \\
5 \cdot 62 \\
6 \cdot 42\end{array}$ & $\begin{array}{l}6 \cdot 66(0 \cdot 65) \\
6 \cdot 12(0 \cdot 64) \\
6 \cdot 75(0 \cdot 81) \\
7 \cdot 01(0 \cdot 79) \\
5 \cdot 78(0 \cdot 71)\end{array}$ & $\begin{array}{l}5 \cdot 69 \\
5 \cdot 16 \\
6 \cdot 15 \\
5 \cdot 77 \\
6 \cdot 66\end{array}$ & $\begin{array}{l}6 \cdot 67(0.71) \\
6.54(0.74) \\
6 \cdot 89(0.82) \\
6.91(0.80) \\
5 \cdot 71(0.59)\end{array}$ \\
\hline
\end{tabular}

${ }^{\star}$ LCMRG1c values below the cut off score.

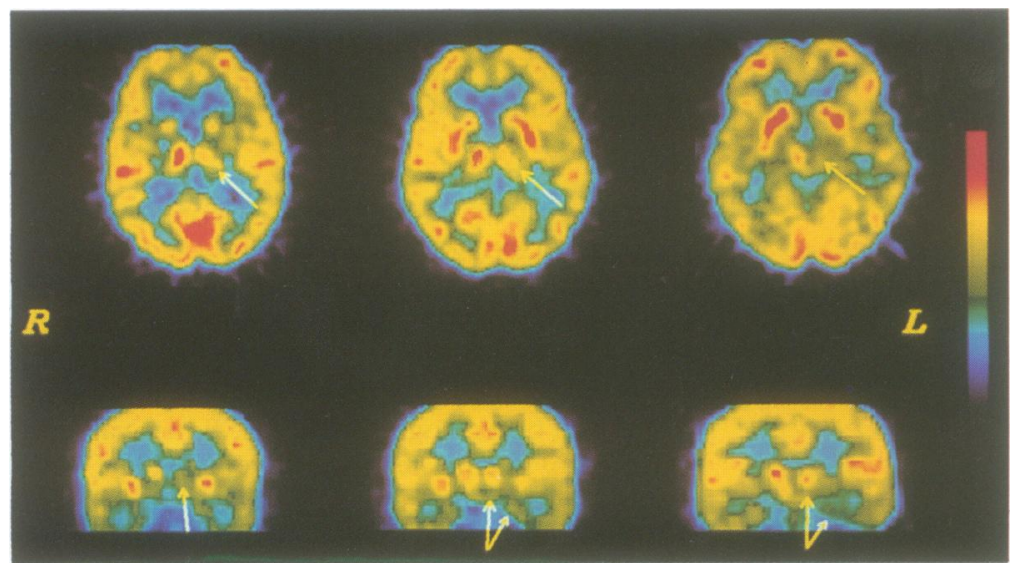

Figure 2 PET showing left thalamic and temporal mesial region hypometabolism (arrows). Top: axial sections; bottom: coronal sections.
(Analyze BRU/Mayo Clinic) on a SUN (SPARC) workstation (see Fazio et $a l^{10}$ for details). Numerical data were obtained from a circular region of interest with a diameter corresponding to 1.5 FWHM $(9.6 \mathrm{~mm})$ manually drawn on all cortical areas, the main subcortical nuclei, and deep structures; average values of local cerebral metabolic values of glucose (LCMRG1c) were then calculated from multiple circular regions of interest included within the major anatomical subdivisions identified on the Talairach and Tournoux atlas (table 4). ${ }^{11}$ The averaged LCMRG1c values for the same regions of interest in eight normal subjects (mean age 55.43 (SD 9.45 years)) were used as control values. Values for LCMRG1c in the patient were considered pathological when outside 2 $\mathrm{SD}$ from corresponding values obtained in normal controls.

Significant hypometabolism (LCMRG1c values below the cut off score of the mean (2 SD)) was present in the thalamus and temporal mesial region on the left side (table 4, fig 2). The thalamus was also divided into three parts to differentiate anterior, middle, and posterior regions. The metabolic reduction was by $24 \%$ and $18 \%$ respectively for the whole left thalamus and the temporal mesial region, compared with the controlateral side. Only the LCMRG1c values in the anterior and middle sectors of the left thalamus were below the cut off scores. The right thalamus showed metabolic values within the normal range, but slightly reduced. Values for LCMRG1c in the frontal, temporal, parietal, and occipital cortex of both cerebral hemispheres were within the normal range.

\section{Discussion}

The history and clinical profile of this patient is characterised by the slow development of an amnesia of moderate intensity, which contrasts with the preservation of excellent intellectual abilities and of normal skills in other cognitive domains (language, perception, praxis, etc). This pattern of deficits is well known in patients with global amnesia and the features of the memory impairment also tally with those classically reported in that condition-namely, dissociation between intact short term memory and impaired long term memory, prevalence of anterograde over retrograde amnesia, preservation of spatial memory in the face of poor recollection of verbal and visual stimuli. What makes the history of the patient remarkable is the early slow progression of the disease and then its stabilisation spanning the period of observation. That in the early years of disease amnesia had developed gradually was the firm belief both of the patient and her relatives. They only disagreed on its onset, that the patient tended to date back to an earlier time than her husband and children. Among the possible causes of amnesia, tumour, encephalitis, alcohol misuse-namely, trauma, infarct, and haemorrhage were ruled out by the patient's history and the negative neurological, CT and MRI 
findings. The slow development of amnesia and the absence of other neurological deficits is suggestive of a degenerative process involving cortical associative areas, although a diagnosis of Alzheimer's or Pick's disease seems unlikely. Amnesia is one of the earliest manifestations of degenerative dementias, but, by the time that the patient comes to the neurologist's attention and is submitted to thorough neuropsychological examination, more widespread deterioration of cognitive functions has usually started. To the best of our knowledge, a case of amnesia that remains "pure" seven years after its onset, without signs of more widespread cognitive decline, has not been reported in follow up studies of Alzheimer's disease.

In recent years, there have been case reports of patients showing a progressive breakdown of a single cognitive ability (language, praxis, visual recognition) with preservation of other mental functions. ${ }^{12}$ The most often reported form is slowly progressive aphasia $^{1}$ and for some of the cases ${ }^{1314}$ there is evidence not only of clinical, but also of pathological autonomy with respect to classic degenerative dementias. We submit that the present case represents an instance of a degenerative process circumscribed to the cortical areas subserving memory function.

Although no alteration in structural anatomy was shown by CT and MRI, the metabolic pattern disclosed by PET is consistent with the assumption of an autonomous disease. It differs from that reported in association with Alzheimer's disease. ${ }^{15}$ Impaired metabolism of temporoparietal cortices in patients with early, possible Alzheimer's disease is a frequent finding and is held to precede the onset of non-memory dysfunction. ${ }^{16}$ These regions were comparatively spared in our patient. Conversely, thalamic metabolism, which is within normal limits in early Alzheimer's disease, ${ }^{17}$ was severely affected. The reduction of glucose metabolism was selectively confined to the left thalamus and the left mesial temporal cortex (hippocampus), which are known to be specifically related to episodic memory function. ${ }^{18}$ As for the thalamus, the anterior and middle parts were particularly involved, even if a selective functional depression in some thalamic nuclei, such as the anterior and dorsomedial nuclei, is beyond the spatial resolution of PET. Thalamic structures involved in memory function include not only the mammillothalamic tracts and anterior nucleus, which are components of the Papez circuit, but also the dorsomedial nucleus and the internal medullary lamina, as suggested by the finding of amnesia after focal thalamic damage. ${ }^{19}$ The temporal mesial hypometabolism is possibly another functional correlate of the severe impairment of episodic memory in this patient. The confinement of damage to the left side may account for the dissociation between impaired verbal memory and preserved spatial memory.

It must be admitted, however, that the concept of degenerative disease, whether diffuse in the associative cortex or confined to some of its sectors, meets with difficulty in accounting for the other feature marking the temporal profile of this patient's disease-namely, the stabilisation of amnesia a few years after its insidious onset. Although the period of observation (three years) may be too short to predict the future course of the disease, this lack of deterioration is at variance with the patterns of relentless development usually found in degenerative processes.

Confronted with a similar clinical picture presented by three patients, Kritchevsky and Squire $^{20}$ opted for an ischaemic aetiology. Amnesia had developed in one week in one patient and in one to two years in two others, and then it remained unchanged for six to seven years. Magnetic resonance imaging showed a profound, bilateral reduction of the hippocampal formation in all of them. It was hypothesised (but not documented) that episodes of hypotension had occurred in the patient who had the shortest onset, and resulted in a reduced blood flow of the hippocampal formation. The same pathophysiological mechanism was tentatively extended to the two patients with the longer development of amnesia, despite the absence of any independent evidence that they had cardiovascular problems. The idea that cerebral blood insufficiency may be responsible for a slowly progressive cognitive decline, not punctuated by a stepwise course, was entertained in the past, but does not find any support in the current body of knowledge on the pathophysiology of cerebrovascular diseases. Nor is it easy to understand why such a mechanism, after having caused a progressive amnesia in the early years of disease, would no longer exert a deleterious effect on memory function in the subsequent six or seven years.

We believe, therefore, that, despite the plateau reached by all these patients in the course of their disease, a circumscribed degenerative process remains a more likely interpretation of their amnesia than an ischaemic aetiology.

Only neuropathological findings will provide an unequivocal answer to the aetiology of these cases. For the time being, we must be satisfied with the contention that slowly progressive amnesia must be added to the gamut of already known monosymptomatic forms of progressive cognitive decline (aphasia, apraxia, agnosia). Its temporal profile is, however, peculiar and requires a close follow up.

This study was supported by grants from CNR and MURST $40 \%$ to EDR. We thank Ms Gillian Jarvis for her careful revision of the English.

1 Mesulam MM. Slowly progressive aphasia without generalized dementia. Ann Neurol 1982;11:592-8.

2 Tyrell PJ, Warrington EK, Frackowiak RSJ, et al. Heterogeneity in progressive aphasia due to focal cortical atrophy. Brain 1990;113:1321-36.

3 De Renzi E. Slowly progressive visual agnosia or apraxia without dementia. Cortex 1986;22:171-80.

4 Dick JPR, Snowden J, Northen B, Goulding PJ, Neary D. Slowly progressive apraxia. Behav Neurol Biol 1989;2. Slowly progressive apraxia. Behav Neurol Biol 1989;2
101-14.

5 Kartsounis LD, Warrington EK. Failure to object 
recognition due to a breakdown of figure-ground discrimination in a patient with normal acuity. Neuropsychologia 1991;29:969-80.

6 De Renzi E, Faglioni P, Ruggerini C. Prove di memoria verbale di impiego clinico per la diagnosi di amnesia. Archivio di Psicologia, Neurologia e Psichiatria 1977;38. 303-8.

7 Bertolani L. Taratura su soggetti normali ed applicazioni in pazienti cerebrolesi di test di memoria visiva. University of Modena, 1992. (MD Thesis.)

8 Costa M, De Renzi E, Faglioni P. Un questionario italiano per lo studio della memoria retrograda. Archivio di Psicologia, Neurologia e Psichiatria 1989;50:735-55.

9 De Renzi E, Faglioni P, Grossi D, Nichelli P. Apperceptive and associative forms of prosopagnosia. Cortex 1991;27:213-21.

10 Fazio F, Perani D, Gilardi MC, Colombo F, Cappa SF Vallar G. Metabolic impairment in human amnesia: PET study of memory networks. I Cereb Blood Flow Metab 1992;12:353-8.

11 Talairach J, Tournoux P. Coplanar stereotaxic atlas of the human brain. Stuttgart: Thieme Verlag, 1988.

12 Duffy JR, Petersen RC. Primary progressive aphasia. Aphasiology 1992;6:1-15.

13 Kirshner HS, Tandridag O, Thurman L, Whitsell WO. Progressive aphasia without dementia: two cases with focal spongiform degeneration. Ann Neurol 1987;22: 527-32.

14 Deruaz JP, Assal G, Peter-Favre $\mathrm{Cl}$. Un cas clinicopathologique d'aphasie progressive. Rev Neurol 1993;149:186-91.

15 Friedland RP, Budinger TF, Ganz E, et al. Region cerebral metabolic alterations in dementia of Alzheimer type positron emission tomography with ${ }^{18}$ Fluorodeoxyglucose. $\mathcal{f}$ Comput Assist Tomogr 1983;7: $590-8$.

16 Haxby JV, Grady CL, Duara R, Schlageter N, Berg G, Rapoport SI. Neocortical metabolic abnormalities preRapoport SI. Neocortical metabolic abnormalities precede non-memory cognitive deficits in ear
type dementia. Arch Neurol 1986;43:882-5.

17 Perani D, Bressi S, Cappa SF, Vallar G, Alberoni M, Grassi F. Evidence of multiple memory systems in the human brain: a $\left[{ }^{18} \mathrm{~F}\right]$ FDG PET metabolic study. Brain 1993;116:903-19.

18 Butters N, Miliotis P. Amnesic disorders. In: Heilman $\mathrm{KM}$, Valenstein E, eds. Clinical neuropsychology. 2nd ed. Oxford: Oxford University Press, 1985:403-51.

19 von Cramon DY, Hebel N, Schuri U. A contribution to the anatomical basis of thalamic amnesia. Brain 1985;108:993-1008.

20 Kritchevsky M, Squire LR. Permanent global amnesia with unknown etiology. Neurology 1993;43:326-32. 